\title{
FOTOGRAFI SEBAGAI REKONSTRUKSI VISUAL DALAM SENI BERCERITA RAKYAT STUDI KASUS "SARIP TAMBAK OSO"
}

\author{
Aryo Bayu Wibisono \\ Aphief Tri Artanto \\ Alfian Candra Ayuswantana \\ Dosen Program Studi Desain Komunikasi Visual, Fakultas Arsitektur dan Desain \\ Universitas Pembangunan Nasional Veteran Jawa Timur \\ Jalan Rungkut Madya, Gunung Anyar, Surabaya \\ No. Hp.:+6281232570791; E-mail: aryobayuw.dkv@upnjatim.ac.id
}

\begin{abstract}
ABSTRAK
Cerita rakyat memiliki gambaran yang menarik untuk digambarkan kembali pada era kemajuan teknologi saat ini, mengingat cerita rakyat atau folklor adalah ciri khas dan kekayaan suatu bangsa. Anti klimaks yang terjadi di Indonesia, cerita rakyat tersebut menghilang karena kurang dimunculkan dan jarang dibicarakan lagi. Salah satu faktornya ialah ketidaktahuan masyarakat terkait kronologis suatu cerita rakyat, terutama di daerahnya masing-masing. Akibatnya, cerita rakyat tersebut menjadi kurang populer kemudian lambat laun menghilang. Padahal cerita rakyat tersebut memiliki banyak muatan tradisi, turun-temurun hingga menjadi semangat kebangsaan bagi wilayah itu sendiri. Beberapa cerita yang hilang ini tentunya perlu rekonsiliasi dari berbagai pihak untuk memunculkan kembali cerita rakyat. Fokus utama dalam penelitian ini adalah menyusun kembali cerita rakyat yang kurang populer di tengah masyarakat. Metode penciptaannya melalui rekonstruksi visual dengan menggunakan perekaman fotografi, kemudian dilanjutkan dengan tahapan eksplorasi, eksperimentasi, sintesis, dan penyelesaian. Metode pengumpulan data dalam penelitian ini menggunakan metode kualitatif, yaitu wawancara, observasi, pendalaman literasi, dan penyusunan artikel ilmiah untuk mendukung pola rekonstruksi visual Sarip Tambak Oso. Penelitian ini adalah model penelitian deskriptif yang bertujuan untuk membuat definisi awal penelitian, kemudian hasilnya dikembangkan lebih lanjut dalam penelitian berikutnya. Penelitian ini mengambil studi kasus cerita "Sarip Tambak Oso" yang berada di wilayah Sidoarjo - Surabaya, yang berjarak 10 menit dari kampus UPN Veteran Jatim. Studi kasus wilayah Tambak Oso dipilih karena wilayah ini termasuk dalam Rencana Strategis (Renstra) pengembangan Tri Dharma kampus UPN Veteran Jatim. Hasil penelitian ini adalah penciptaan fotografi yang berisi rekonstruksi tahapan cerita rakyat yang hilang, kemudian dimunculkan dalam bentuk serial fotografi yang saling berurutan. Tujuannya ialah untuk memudahkan peneliti, masyarakat atau praktisi seni membaca atau mengembangkan cerita rakyat sebagai satu kesatuan yang dapat dilihat secara saksama.
\end{abstract}

Kata kunci: fotografi, visual, cerita rakyat, "Sarip Tambak Oso"

\section{ABSTRACT}

Photography as a Visual Reconstruction in the Art of Folktale Storytelling: A Case Study of "Sarip Tambak Oso". Folklore has an interesting depiction to be portrayed in this era of technological advancement, considering that folktale or folklore is a nation's characteristic and treasure. However, some folklores in Indonesia seemed to be anticlimaxes for they have been disappeared and no longer present, not to mention that it is rarely discussed. This might happen due to some factors, one of which is the chronological ignorance of a story, especially in their own culture. Thus, the folktales became less popular and slowly disappeared. What a pity that the folktales contain a lot of values of tradition, passed down from one to the next generations that it could become the nation spirit. Some of these missing stories certainly need a reconciliation from various parties to bring back the lost or unpopular folk tales. 
Therefore, this study aims to restore the existence of a folk tale that is lost or no longer popular. The method conducted for this photography creation was the visual reconstruction of folklore, using the photographic recording method, followed by exploration, experimentation, synthesis, and finishing. Data collecting for this research was conducted using qualitative methods, namely interview, observation, literary comprehension, as well as composing a publication of academic article to support the visual reconstruction pattern of Sarip Tambak Oso. This research is a descriptive research model that aims to make an initial definition of the study, and then the results could be further developed in subsequent studies. This research brought up the case study of "Sarip Tambak Oso," which is in the Sidoarjo - Surabaya area, a 10 minutes away from UPN Veteran East Java. This area was chosen because Tambak Oso was also included in the Strategic Plan for the development of the Tri Dharma UPN Veteran East Jawa Timur. The result of this research is a photography creation containing a reconstruction of the folktales stages which once were missing, but now they are presented in a sequential photo series. This way, it could promote an ease for researcher, community, and art practitioners to read or to develop the folktales in a holistic way.

Keywords: photography, visual, folktale, "Sarip Tambak Oso"

\section{PENDAHULUAN}

Kebudayaan setiap negara selalu memiliki cerita rakyat yang khas. Meskipun masih satu rumpun dalam suatu bangsa, cerita rakyatnya pasti memiliki perbedaan baik dari segi ceritanya atau latar belakangnya. Menurut Herlina, (2005:19), pengertian cerita rakyat adalah cermin kehidupan masyarakat lama yang berlandaskan dongeng, mitos, sage, dan legenda. Yuwono (2007:27) menegaskan dongeng adalah cerita tentang sesuatu hal yang tidak masuk akal, seringkali bersifat fantastik, tidak benar-benar terjadi atau bersifat khayalan. Arti mitos adalah cerita masyarakat setempat yang terkait dengan roh-roh, dewa-dewi atau makhluk halus. Sage adalah cerita kegagahan seorang pahlawanan dalam sejarah, sedangkan legenda adalah dongeng terkait peristiwa alam yang ajaib dan aneh.

Cerita rakyat adalah bagian dari kekayaan budaya yang intangible (Koentjaraningrat, 2009:64). Hal ini disampaikan dan tertuang dalam World Intellectual Property Organization (WIPO) terkait cerita rakyat yang diartikan sebagai traditional knowledge:

"Tradition based literary, artistic or scientific works, performances, inventions, scientific discoveries, designs, marks, names, and symbols, undisclosed information, and, all other tradition based innovations and creations resulting from intellectual activity it the industrial, scientific, literary or artistic fields."

Antiklimaks dengan perkembangan cerita rakyat di negara Indonesia, banyak dari cerita rakyat yang terkikis dan kurang populer lagi dalam masyarakat (Gusal, 2015:2). Hal tersebut menjadikan beberapa cerita rakyat itu hilang, walaupun cerita rakyat tersebut pernah ada di wilayah itu. Menurut Gibbs (2018:3), sebenarnya cerita rakyat memiliki wisdom, nilainilai kelokalan budaya yang melekat sangat kuat dan identik di setiap daerah, apalagi di negara Indonesia. Kehilangan suatu cerita rakyat, berarti suatu negara sedang kehilangan kebudayaan yang intangible (Kartika, 2018:381).

Peraturan negara Indonesia sudah berupaya membentuk undang-undang untuk melestarikan cerita rakyat melalui dan tertuang dalam UndangUndang Nomor 5 Tahun 2017, pasal 5 yang memuat objek kemajuan kebudayaan meliputi: (a) tradisi lisan, (b) manuskrip, (c) adat istiadat, (d) ritus, (e) pengetahuan tradisional, (f) teknologi tradisional, (g) bahasa, (h) permainan rakyat, dan (i) olahraga tradisional. Dalam pasal tersebut, 
cerita rakyat terdapat dalam pasal 5 huruf a, yang memuat tradisi lisan, yakni sejarah lisan, dongeng, pantun, rapalan, dan cerita rakyat.

Pembahasan fotografi dalam cerita rakyat pernah disampaikan dalam sebuah karya, oleh fotografer dari Indonesia yang bernama Rio Wibowo, atau yang dikenal sebagai "Rio Motret" dengan tajuk pameran berjudul "AlKisah" pada tahun 2015.
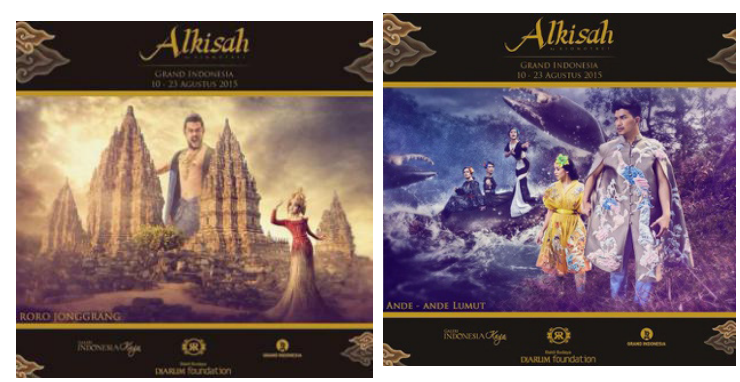

Gambar 1 Merekam cerita rakyat melalui teknik foto pada tahun 2015 (Sumber: Pinterest.com)

Selain itu, manifestasi fotografi dalam tajuk cerita rakyat juga pernah diulas oleh fotografer Diego Zapatero, yang berkebangsaan Spanyol dengan cerita rakyat berlatar belakang tarian berjudul "Panji". Menurut data yang ada, metode penciptaan fotografi dalam cerita rakyat ini menggunakan teknik repro dengan foto lama dalam visualnya terinspirasi dari fotografer keraton tahun 1884 karya Kasian Chepas.

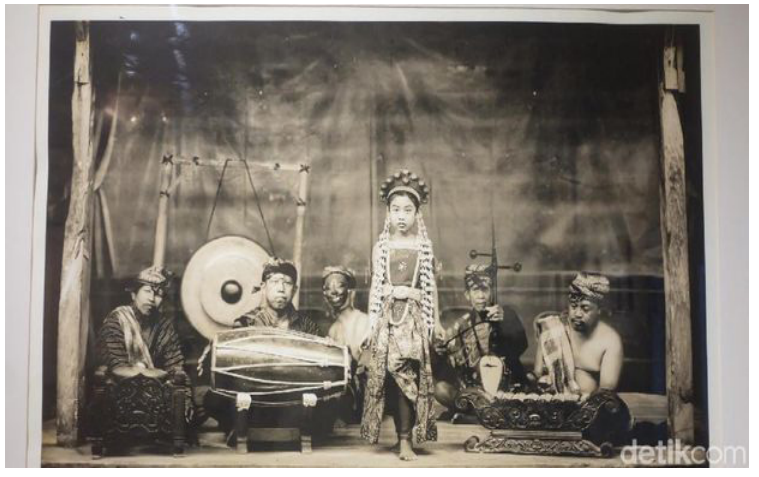

Gambar 2 Contoh Visual Foto Panji oleh Diego Zapatero (Sumber: detik.com, didownload pada 17 Mei 2020).

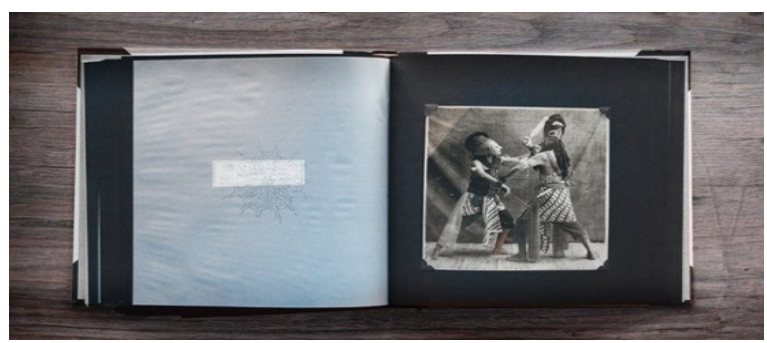

Gambar 3 Buku Karya Diego Zapatero ; (Sumber : http:// diegozapatero.photo/shop/; diunduh pada 17 Mei 2020)

Pertanyaan dalam tajuk penelitian ini adalah mengapa cerita rakyat harus diteliti dengan teknik rekonstruksi melalui fotografi. Mullen (1998:50) memberikan pendapat jika fotografi dan sains telah memiliki sejarah yang panjang dalam menemukan hal-hal yang belum terungkap dengan realitas dan visual yang natural. Bahkan fotografi telah memberikan andil selama dua dekade melalui transformasi fungsi secara teknis dan berkontribusi penuh terhadap kemajuan kebudayaan dunia (Galloway, 1992:329).

Hal ini berarti memungkinkan fotografi dapat memberikan informasi dan rekam jejak terhadap suatu kebudayaan yang kurang populer atau bahkan hampir hilang, seperti cerita rakyat. Bisa saja kebudayaan tersebut hilang secara perlahan, maka melalui hasil rekam fotografi dapat melestarikannya. Artinya pola fotografi sangat mungkin memiliki pendekatan yang realis terhadap visual cerita rakyat karena memiliki faktor spectactor (yang melihat) dan spectrum (yang dilihat) (Barthes dalam Ajidarma, 2016:28).

Sementara itu, di sisi lain fotografi dengan tema-tema cerita rakyat masih belum menyeluruh selama ini, kebanyakan masih mengandalkan gaya melalui ilustrasi untuk mengomunikasikannya (Janottama \& Putraka, 2017:27; Arsita \& Aji, 2020:39). Atau di sisi lain cerita rakyat yang selama ini muncul, 
banyak yang bertransformasi dalam bentuk video Ludrukan (offline atau online di jejaring sosial Youtube) atau animasi (Surahman, 2016).

Sebenarnya tidak masalah cerita rakyat berkembang dengan teknik yang berbeda-beda seperti halnya pernyataan di atas, tetapi perlu adanya kesepahaman terkait tatanan visual, alur cerita, penokohan, dan pengembangannya. Dalam hal ini tentu perlu ada sinergitas dari berbagai pihak untuk mengangkat kembali setiap cerita rakyat yang hilang, atau yang tidak dikenali lagi di wilayah masing-masing. Oleh karena itu, kasus ini perlu ada riset fotografi yang mendalam, berjenjang, dan merumuskan aspek yang saling terkait untuk merekontruksi kembali gaya visual hingga pengaplikasiannya. Selain itu, dalam model penelitian fotografi harapannya muncul spirit baru dalam "bercerita rakyat" (Sopudin, 2019:104).

Sosok Sarip Tambak Oso diangkat sebagai studi kasus dalam penelitian ini, atas dasar temuan ketika melakukan observasi dan wawancara yang dilakukan di Tambak Oso, Waru, Sidoarjo. Hasil uji kuesioner, observasi, dan wawancara dengan sesepuh dan sejumlah warga di Desa Tambak Oso menyimpulkan bahwa masyarakat di sana tidak mengetahui asal- muasal cerita "Sarip Tambak Oso" berasal dari wilayah Desa Tambak Oso. Justru cerita Sarip Tambak Oso ini terkenal dalam Ludrukan untuk acara hajatan masyarakat kelas menengah ke bawah, seperti sunatan atau pernikahan di kampung-kampung wilayah luar kota Surabaya dan Sidoarjo. Salah satunya di kota Mojokerto, Jombang, Pasuruan.

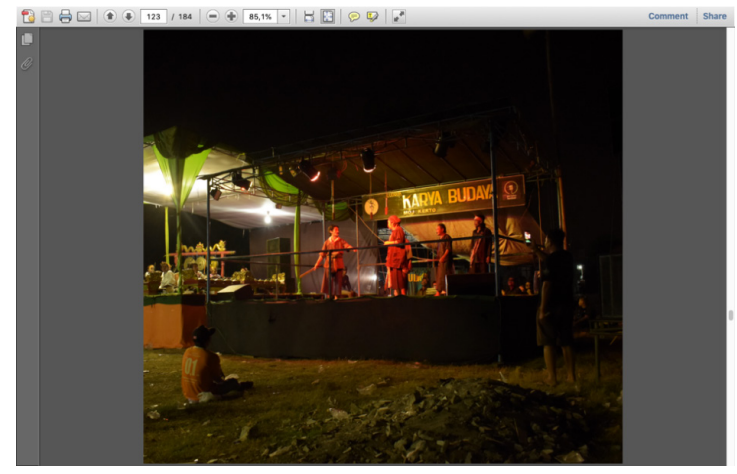

Gambar 4 Ludrukan Sarip Tambak Oso Karya Budaya

(Olah Foto Dokumentasi oleh Aryo Bayu W. dan Maman Fajruzzaman, April 2019.

Lokasi Kec. Bangsal, Kota Mojokerto)

Sosok Sarip Tambak Oso diceritakan terkenal sebagai sosok kepahlawanan yang dalam bahasa Indonesia sebagai sage, yakni cerita rakyat yang berkisah tentang kegagahan seorang pahlawanan dalam sejarah (Yuwono, 2007:27). Disadur dari buku Balai Perpustakaan dan Bahasa, Pemerintahan Kota Surabaya, Sosok Sarip Tambak Oso adalah salah satu pemuda yang dapat menjadi tokoh inspirator perjuangan melawan penjajah Belanda kala itu. Yang menjadi epik cerita rakyat ini adalah (selain pertarungannya dengan centengcenteng pihak Kompeni Belanda), salah satu yang sering diangkat dalam Ludrukan adalah tentang penghargaan dan penghormatannya anak muda kepada sosok ibu, sesuatu hal yang jarang terjadi untuk pemuda saat ini (Mashuri \& Nilofar, 2008:67).

\section{METODE PENCIPTAAN}

Untuk mendukung metode penciptaan visual, dalam penelitian ini akan menggunakan tahapan fishbone seperti gambar sebagai berikut, 


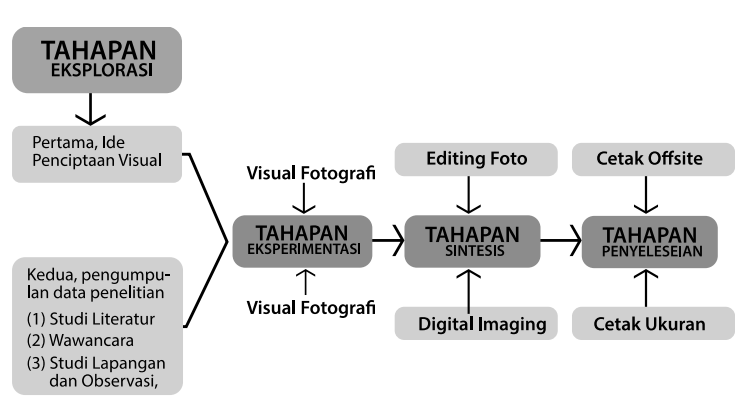

Gambar 5 Infografis Metode Penciptaan

\section{Tahap Eksplorasi}

Pertama, ide penciptaan visual. Lokasi Desa Tambak Oso dan kampus UPN Veteran Jatim (UPN-JT) tidak terlalu jauh, yakni hanya berjarak 10 menit saja ketika berkendara. Hal ini yang menjadi ide penciptaan visual dalam penelitian ini. Sebagai kampus yang memiliki visi bela negara, Program Studi DKV, UPN Jatim tentunya berkewajiban melestarikan dan mengembangkan cerita rakyat yang notabene sering muncul dalam ludruk-ludruk atau ceritacerita yang turun-temurun.

Penelitian ini juga sejalan dengan Rencana Strategis (RENSTRA) kampus UPN Jatim, yang memiliki pengembangan Ilmu Pengetahuan dan Teknologi (IPTEK) dan Sosial Budaya dan Seni (SOSBUDSEN) di wilayah pesisir Surabaya dan sekitarnya. Dengan demikian, dampak dari penelitian ini akan memberikan keberlanjutan ke pengembangan seni dan kebudayaan, khususnya cerita khas Jawa Timuran.

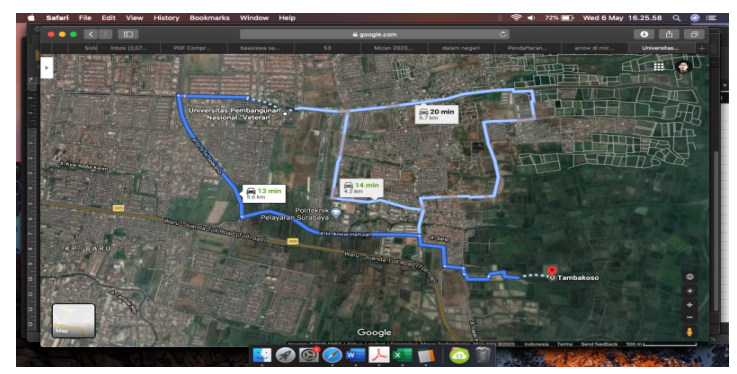

Gambar 6 Jarak lokasi Kampus UPNVJT dengan Lokasi Cerita Sarip Tambak Oso

(Diunduh pada Google Maps 15 Mei 2020)
Cerita rakyatyang terpilih dalampenelitian ini adalah Sarip Tambak Oso. Beberapa hal yang dianggap penting dalam pemilihan cerita Sarip Tambak Oso adalah perannya yang melegenda dalam ludruk-ludruk Obyong (pentas ludruk yang berpindah-pindah) atau pentas seni peran daerahdaerah di Jawa Timur.

Namun, hal ini berbanding terbalik dengan kondisi di wilayah Tambak Oso, yang menurut literatur adalah lokasi Sarip berjuang melawan Belanda. Cerita Sarip Tambak Oso justru tidak dikenal di wilayahnya sendiri (di wilayah Tambak Oso), masyarakatnya cenderung abai dan hanya mengetahui dari cerita-cerita masyarakat terdahulu. Hal ini dibuktikan melalui wawancara dengan sampling, pihak Pemuda Karang Taruna Tambak Oso, dan kuesioner yang disebar wilayah Tambak Oso sebanyak 75 responden. Masyarakat yang mengenal Sarip Tambak Oso (57\%), sedangkan tidak mengenalnya (40\%). Mengenal cerita Sarip dari orang tua (41\%), Ludruk (13\%), rekan (7\%), literatur (28\%), dan media (4\%). Masyarakat Tambak Oso tidak mengetahui jika legenda hidup ini di wilayah mereka (69\%), sedangkan yang tahu cerita Sarip (17\%). Sikap masyarakat Tambak Oso jika dihidupkan kembali sosok Sarip: sangat sangat suka 59\%, suka 8\%, (biasa 1\%, tidak suka $1 \%$, dan sangat tidak suka 3\%. Sikap masyarakat Tambak Oso ketika cerita digali kembali adalah: sangat setuju 56\%, setuju $12 \%$, ragu-ragu $13 \%$, tidak setuju 3\%, sangat tidak setuju 0\%. Masyarakat Tambak Oso ingin mendukung budaya asli cerita rakyat (75\%), sedangkan tidak ingin mendukung (4\%).

Kedua, pengumpulan data penelitian untuk mendukung pola rekonstruksi visual dalam cerita rakyat Sarip Tambak Oso, memerlukan lokasi dan pendataan wilayah yang sesuai dengan wawancara dan observasi 
sebelumnya. Data tersebut dilakukan dengan cara sebagai berikut.

(1) Studi literatur. Studi literatur ini dilakukan dengan pendataan cerita Sarip Tambak Oso yang memiliki beberapa versi. Untuk itu, versi dalam penelitian ini akan mengacu pada: (a) Buku Balai Pusat Bahasa Jawa Timur Kota Surabaya. Buku tersebut berjudul Peran Ibu dalam Cerita Sarip Tambak Oso. Buku ini tidak saja membahas cerita dan latar belakang Sarip Tambak Oso yang melawan Belanda, tetapi juga menginformasikan karakter moral Sarip. Selain itu, dalam literatur juga memberikan informasi kondisi dan geografis daerah perbatasan Surabaya dan Sidoarjo yang menjadi latar belakang cerita rakyat tersebut dan (b) jurnal-jurnal yang merujuk pada cerita rakyat Sarip Tambak Oso.

(2) Wawancara. Hasil data tentang Sarip Tambak Oso yang didapatkan dari literatur, kemudian dilakukan audiensi dari wawancara melalui: (a) Kepala Desa Tambak Oso, Bapak H. Imam Sulbani, S.H. untuk mengetahui latar belakang cerita Sarip Tambak Oso dan data geografis wilayah Tambak Oso, mulai dahulu hingga sekarang; (b) Wawancara dilakukan kepada pemilik Ludruk Karya Budaya, yaitu Bapak Edi Karya, sebagai sutradara dan penata artistik ketika pementasan Ludruk Sarip Tambak Oso. Tujuan wawancara ini adalah untuk mendapatkan plot alur cerita, pendalaman data sosok Sarip Tambak Oso beserta sosok lainnya, dan sinkronisasi data yang didapatkan tentang Sarip Tambak Oso; dan (c) wawancara yang terakhir ialah kepada pemeran Sarip Tambak dalam pementasan seni Ludrukan, yaitu Kukun Triyoga. Tujuan wawancara ini untuk mengetahui pola cerita dan karakter sosok Sarip Tambak Oso yang selama ini diperankan olehnya. Selain itu, juga untuk mengetahui sosok musuh Sarip, centeng Belanda yang terkenal saat itu, yakni Paidi sang kusir dokar, serta sepak terjang Kompeni Belanda pada saat itu.

(3) Studi Lapangan dan Observasi. Berdasarkan cerita dalam literatur dan proses wawancara, tahapan studi lapangan adalah untuk melakukan penyamaan persepsi antara suasana geografis untuk pemotretan, setting lokasi dan mencari sosok karakter (protagonis dan antagonis), dan suasana yang sesuai dengan narasi yang sudah mendapatkan hasil sebelumnya agar sesuai dengan cerita dalam sudut pandang penelitian. Observasi untuk mendukung plot alur cerita Sarip Tambak Oso melalui Ludrukan dalam Video Youtube milik Ludruk Malinda kota Malang (Malinda, 2018).

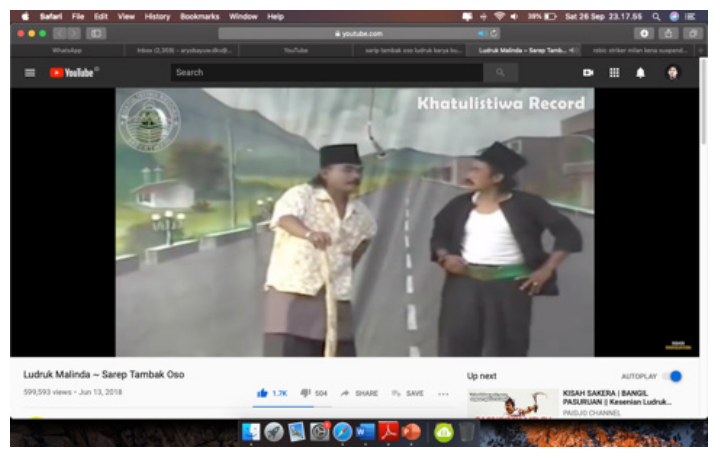

Gambar 7 Gambar Video Ludruk Malinda. (Diunduh pada 17 Agustus 2020)

\section{Tahap Eksperimentasi}

Tahapan eksperimentasi penciptaan visual ini terkait pelaksanaan dan uji coba pemotretan di luar atau dalam studio. Tahapan pemotretan ini dilakukan secara terjadwal, sesuai dengan sinopsis yang terangkum dari pengumpulan data menurut hasil wawancara dan observasi. Pemotretan terjadwal menggunakan metode shoot script, yakni menentukan objek dan atribut apa yang dipotret terlebih dahulu yang terbagi dalam sesi sehingga kemunculan visualnya lebih terkonsep (Wulandari \& Maryani, 2017:62). 
Peralatan yang dibutuhkan dalam sesi pemotretan ini ada dua, yakni kebutuhan outdoor dan indoor. Untuk kebutuhan outdoor akan menggunakan peralatan silver reflector; strobist merk Yong Nuo YN560 III; lensa Nikon 12-24 mm, 80-200 mm, 50 mm, 85 mm; dan kamera DSLR Nikon D750. Untuk indoor menggunakan lampu empat studio berkapasitas $1200 \mathrm{~V}$, reflector, lensa $50 \mathrm{~mm}$, dan DSLR Nikon D750.

\section{Tahap Sintesis}

Setelah melalui tahapan eksperimentasi, tahapan berikutnya adalah pemilihan dan editing visual dari hasil pemotretan outdoor dan indoor. Hasil file mentah yang terpilih dilakukan proses editing foto, dan olah digital imaging pada software Adobe Photosop. Olah foto ini perlu karena file yang tersimpan dalam kamera DSLR Nikon D750 adalah file RAW berformat Nikon Electronic Format (NEF).

Olah foto yang sudah selesai melalui editing software Adobe Photosop kemudian berlanjut ke penyusunan tahapan cerita rakyat untuk layouting melalui software Adobe InDesign. Di sofware Adobe InDesign penataan rekonstruksi fotografi secara estetis dalam bentuk tahapan demi tahapan, dari alur plot awal cerita hingga akhir cerita Sarip Tambak Oso.

\section{Tahap Penyelesaian}

Tahap akhir dari riset ini adalah berwujud visual yang tersusun rapi sesuai kronologis cerita Sarip Tambak Oso. Tujuan dari perwujudan kronologi dalam visual dalam penelitian adalah untuk memudahkan penikmat seni atau pelaku seni menyadur kembali pola cerita yang tersusun rapi. Pola layout terpilih untuk hasil akan memaksimalkan pola gambar landscape. Visual landscape ini memiliki ukuran dimensi $50 \mathrm{~cm} \mathrm{x}$
$24 \mathrm{~cm}$. Warna yang terpilih dalam visual adalah tone sephia untuk memaksimalkan kesan dramatis dalam cerita rakyat.

Hasil visual akan dicetak melalui digital printing laser menggunakan kertas matte paper dan kover laminasi dof. Format gambar dan teks dalam Adobe InDesign adalah CMYK, untuk memudahkan jika produksi massal ke penerbitan. Hasil visual ini nantinya dapat berkembang ke berbagai macam luaran seperti film, komik, cerpen, atau novel grafis. Oleh karena itu, perlu ada susunan yang sistematis agar penelitian ini dapat berkelanjutan ke depannya.

\section{PEMBAHASAN}

\section{Visual Karakter}

Menurut Wardhani (2019:35), sosok Sarip Tambak Oso digambarkan sebagai pria muda asal Sidoarjo, Surabaya, Jawa Timur berlatar belakang Islam abangan yang berwatak keras namun jujur, serta memiliki sifat membela masyarakat kelas bawah dari penjajah Belanda. Model gaya busana dari Sarip Tambak Oso berdasarkan literasi dan observasi ialah berbaju kaos putih merah, berpadu dengan luaran lengan panjang bewarna hitam dan memakai peci hitam. Sarip memiliki senjata dalam pertarungan berupa "belati”, tetapi diriwayatkan oleh narasumber yang lain memakai senjata pisau dengan ukuran besar, menyerupai golok.

Untuk analisis data, musuh-musuh Sarip adalah centeng Belanda yang bergaya busana tidak jauh berbeda, yakni memakai peci hitam, baju dominan hitam. Senjatanya adalah belati, tongkat, atau clurit. Menurut Widodo (2013:204), terminologi dari penceritaan karakter Sarip Tambak Oso mencerminkan gaya streotype masyarakat Arek pada tahun 1930-an, yakni subkultur wilayah Surabaya, Sidoarjo, Gresik, Pasuruan, dan Malang (Abdillah dalam Sholihatin, 2013: 162). Sementara itu, gaya 
prajurit Belanda memiliki baju khas kompeni, yakni sepatu boot, baju warna cokelat atau biru, dan memiliki topi yang melingkar berwarna cokelat.

\section{Pendalaman Wilayah Tambak Oso}

Kondisi geografis wilayah Tambak Oso sejak zaman Belanda mayoritas adalah tambak. Lokasinya dekat dengan laut menghadap ke arah utara Pulau Madura sehingga masyarakatnya juga berprofesi sebagai nelayan. Hasil panennya kurang melimpah dikarenakan faktor tanah tambak. Meskipun ada hasil buah pisang dan pepaya di Tambak Oso. Masyarakat Tambak Oso sejak zaman dahulu juga beternak ayam dan kambing selain mengelola tambak (Purwaningsih, 2019).

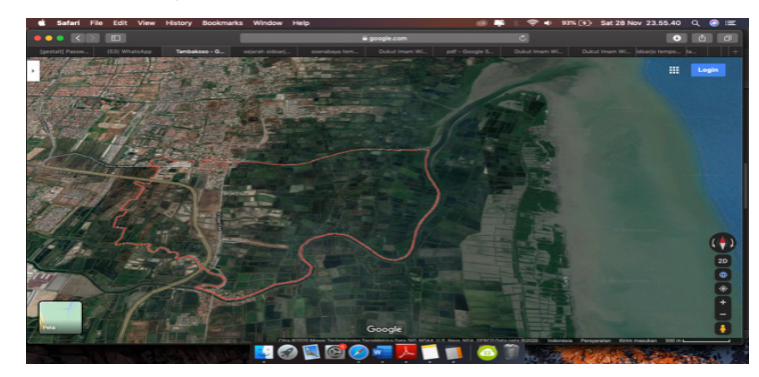

Gambar 8 Lokasi Tambak Oso (Diunduh pada Google Maps ,23 Mei 2020).

\section{Plot Alur Cerita Sarip Tambak Oso}

Alur cerita Sarip Tambak Oso memiliki tahapan yang penting dan tidak boleh terputus. Menurut hasil analisis data, pembahasan tahapan terbagi atas tiga tahapan, yakni pertama awal perlawanan Sarip ke Belanda, kedua pertarungan Sarip, ketiga kematian Sarip. Keseluruhan cerita Sarip Tambak Oso berjumlah 12 chapter. Masing-masing chapter tersebut nantinya dapat akan berkembang sesuai dengan narasi dari hasil pengumpulan data. Alur cerita penting yang harus muncul adalah sebagai berikut,
Tabel 1 Alur cerita Sarip Tambak Oso

\begin{tabular}{cll}
\hline No. & Chapter & Uraian/Plot Cerita \\
\hline I & Lurah Gedangan & Lurah Gedangan menagih pa- \\
& Mengancam Ibu & jak kepada masyarakat, salah \\
& Sarip & satunya menagih secara kasar \\
& & kepada Ibu Sarip
\end{tabular}

\begin{tabular}{ll}
\hline $\begin{array}{l}\text { Terbunuhnya Lu- } \\
\text { rah Gedangan }\end{array}$ & $\begin{array}{l}\text { Melalui pertikaian dengan } \\
\text { Lurah Gedangan, Sarip mem- } \\
\text { bunuh Lurah Gedangan. }\end{array}$ \\
\hline $\begin{array}{l}\text { Sarip menye- } \\
\text { lamatkan ibunya }\end{array}$ & $\begin{array}{l}\text { Sarip menyelamatkan ibunya } \\
\text { yang telah dilukai oleh Lurah } \\
\text { Gedangan. }\end{array}$ \\
\hline $\begin{array}{l}\text { Persekongkolan } \\
\text { Paman Sarip }\end{array}$ & $\begin{array}{l}\text { Paman Sarip berkomplot den- } \\
\text { gan Belanda untuk menang- } \\
\text { kap Sarip hidup atau mati. }\end{array}$ \\
\hline Paidi Musuh & $\begin{array}{l}\text { Paidi adalah centeng Belan- } \\
\text { da, suruhan Paman Sarip kaki } \\
\text { tangan Belanda untuk mem- } \\
\text { bunuhnya. }\end{array}$ \\
\hline Duel Sarip dan & $\begin{array}{l}\text { Duel Sarip dan Paidi di- } \\
\text { menangkan Paidi, lalu Sarip } \\
\text { Paidi Jilid I }\end{array}$ \\
& $\begin{array}{l}\text { terbunuh di pinggir kali Tam- } \\
\text { bak Oso. }\end{array}$ \\
\hline Sarip Hidup & $\begin{array}{l}\text { Ibu Sarip tidak rela anaknya } \\
\text { tewas karena dibunuh Paidi. }\end{array}$ \\
Lagi & Suatu keajaiban, Sarip kemu- \\
& dian hidup kembali karena \\
& ibunya berteriak Sarip belum \\
& waktunya meninggal. \\
&
\end{tabular}

\begin{tabular}{ll}
\hline $\begin{array}{l}\text { Sarip Pahlawan } \\
\text { Masyarakat ter- } \\
\text { tindas }\end{array}$ & $\begin{array}{l}\text { Sarip kerap menghadang jara- } \\
\text { han pajak. Dari hasil meram- } \\
\text { pas hak rakyat oleh centeng } \\
\text { Belanda, dan tidak jarang } \\
\text { Sarip menyatroni rumah Be- } \\
\text { landa untuk mengambil kem- } \\
\text { bali harta rampasan tersebut, } \\
\text { kemudian dibagikan ke mas- } \\
\end{array}$ \\
& yarakat. \\
& $\begin{array}{l}\text { Sarip membunuh Paidi dalam } \\
\text { duel keduanya, pascabangkit } \\
\text { dari kematian. }\end{array}$ \\
\hline Duel Sarip dan & \\
Paidi Jilid II & Paman Sarip Tambak Oso \\
& membocorkan kekuatan Sar- \\
& ip yang tidak bisa mati dalam \\
Pengkhianatan & setiap pertarungan kepada \\
oleh Paman & Belanda. Rahasianya ada da- \\
Sarip & lam Ibu Sarip. \\
& \\
\hline &
\end{tabular}




\begin{tabular}{ll}
\hline $\begin{array}{l}\text { Ibu Sarip dijebak } \\
\text { Belanda dan } \\
\text { tewas }\end{array}$ & $\begin{array}{l}\text { Ibu Sarip ditangkap dan Be- } \\
\text { landa merencanakan siasat } \\
\text { busuk untuk membunuh Ibu } \\
\text { Sarip agar sarip dapat tewas } \\
\text { di tangan Belanda. }\end{array}$ \\
\hline $\begin{array}{l}\text { Sarip tewas } \\
\text { ditembak }\end{array}$ & $\begin{array}{l}\text { Pasukan/tentara Belanda } \\
\text { mengepung Sarip dalam per- } \\
\text { tarungan sengit dan berhasil } \\
\text { membunuhnya. }\end{array}$ \\
\hline
\end{tabular}

\section{Perekaman Awal Perlawanan}

Perekaman fotografi pada tahapan awal perlawanan akan mengambil perspektif Lurah Gedangan yang memberikan seruan ancaman kepada Ibu Sarip. Situasi wilayah dalam visual digambarkan melalui kondisi Tambak Oso yang kering dan dominasi tambak pada sekitarnya. Bentuk rumah besek atau gedek di latar belakang Ibu Sarip merepresentasikan kemiskinan rakyat pada saat itu.

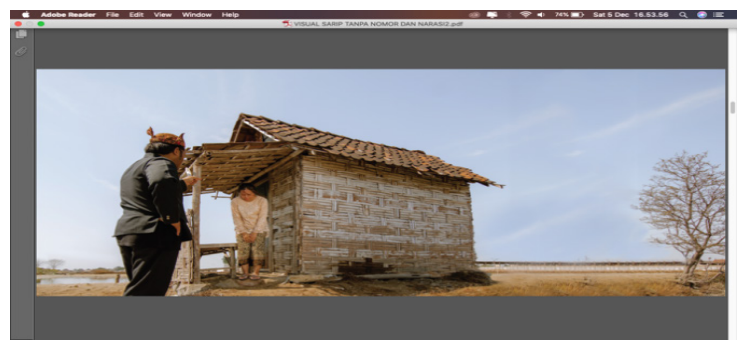

Gambar 9 Lurah Gedangan mengancam Ibu Sarip

(Perekaman gambar dilakukan 10 Juli 2020)

$\begin{array}{cccc}\text { Situasi pemotretan } & \text { yang } & \text { kedua } \\ \text { menggambarkan Sarip melawan } & \text { Lurah }\end{array}$ Gedangan dan berhasil membunuhnya. Situasi wilayah yang menjadi latar belakang adalah hutan Mangrove, dengan latar belakang pohon Lamtoro yang banyak ditemukan di wilayah Tambak Oso.

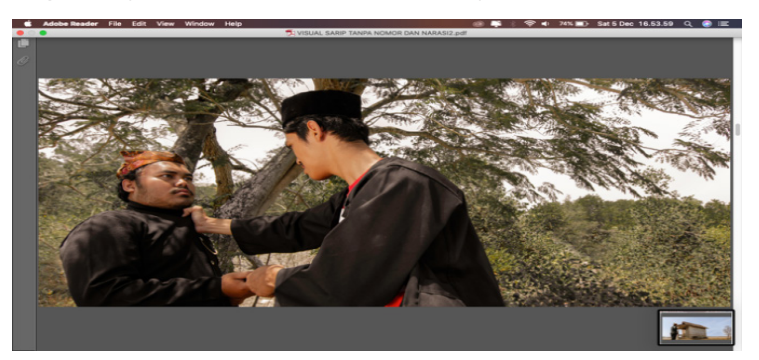

Gambar 10 Lurah Gedangan berkelahi dengan Sarip Tambak Oso (Perekaman gambar dilakukan 12 Agustus 2020).
Pemotretan visual bagian awal juga memberikan gambaran kepada Paman Sarip yang berkomplot kemudian menginstruksikan centeng (jagoan Belanda) bernama Paidi, untuk membunuh Sarip. Situasi visual foto ini berlatar belakang rumah Paman Sarip, yang berlatar belakang tembok. Konotasi ini menunjukkan strata Paman Sarip yang terpandang saat itu.

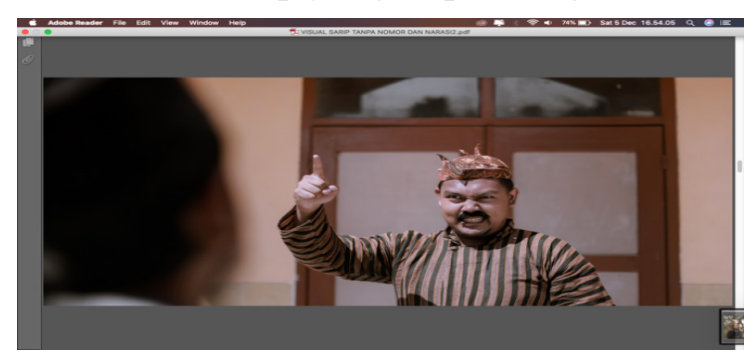

Gambar 11 Paman Sarip yang mendukung Belanda mulai menyuruh Paidi untuk membunuh Sarip

(Perekaman gambar dilakukan 13 Agustus 2020).

Baju Paman Sarip memakai kain lurik bermotif "sapit urang". Arti motif ini menandakan siap berkonfrontasi dengan pihak lain (Afrianto, 2014:117). Motif ini merepresentasikan visual kaki tangan Belanda, yang berkiblat pada gaya Jawa Tengahan yang saat itu lebih modern dibandingkan kota Surabaya atau Sidoarjo.

\section{Perekaman Pertarungan Sarip}

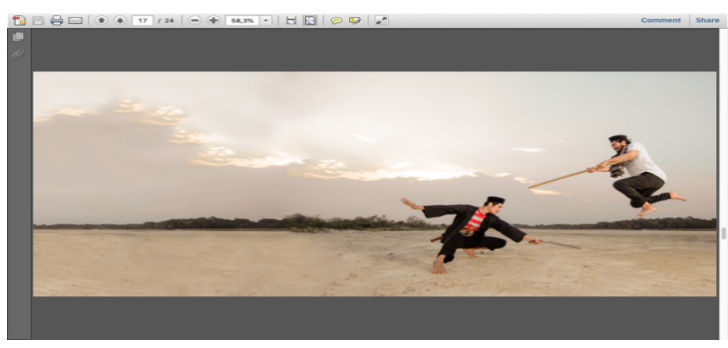

Gambar 12 Pertarungan Sarip dan Paidi jilid I dimenangkan oleh Paidi (Perekaman gambar dilakukan 16 Agustus 2020).

Pertarungan Sarip Tambak Oso yang banyak dikisahkan dalam cerita Ludrukan adalah pertarungannya dengan Paidi. Pertarungan ini terjadi dua kali, pertama Sarip 
terbunuh di pinggir Sungai Tambak Oso. Sarip terbunuh dan jasadnya ditemukan oleh ibunya, tetapi menurut Sarip kemudian hidup lagi karena kematiannya tidak diridai oleh sang ibu.

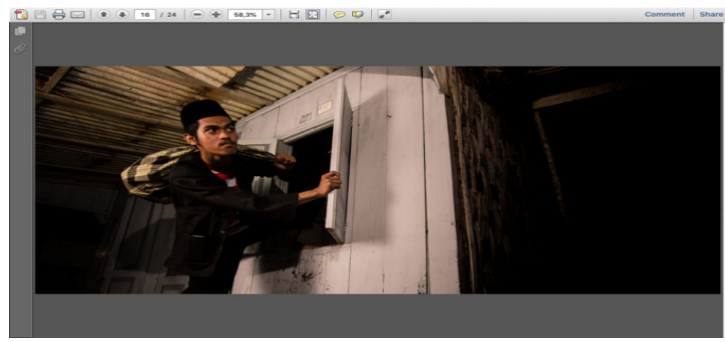

Gambar 13 Visual Sarip sedang menjarah Komplotan

Belanda (Perekaman gambar dilakukan 21 Agustus 2020).

Maka dari itu, sekembalinya Sarip dari kematian, Sarip melakukan serangkaian perlawanan kepada pihak-pihak yang berkomplot dengan Belanda. Salah satu yang terkenal dalam riwayat adalah mengambil harta kroni Belanda, yang sebenarnya adalah hak milik masyarakat saat itu untuk dibagi-bagikan kepada rakyat miskin. Gambaran dari visual ini adalah pemotretan pada malam hari, dengan visual Sarip keluar dari jendela rumah.

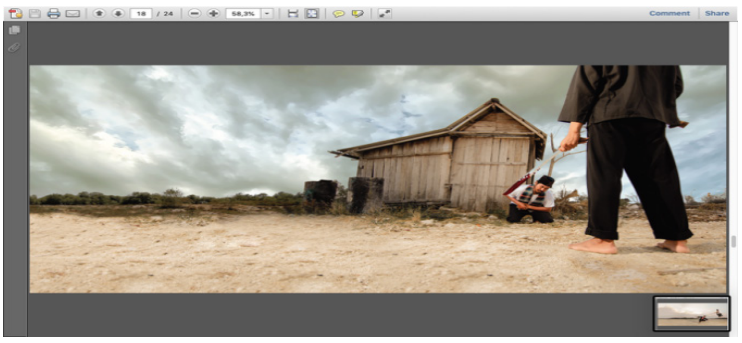

Gambar 14 Visual Paidi terbunuh (Perekaman gambar dilakukan 27 Agustus 2020).

Dalam petualangannya merepotkan Belanda saat itu, Paidi ditugaskan kembali untuk membunuh Sarip. Keduanya bertemu di wilayah pertambakan, yang menjadi persembunyian Sarip. Sewaktu pertarungan kedua, Paidi mengalami kekalahan dan terbunuh oleh Sarip. Representasi penggambaran visual ini melalui sosok Paidi yang bersujud memegangi perutnya, sedangkan Sarip berdiri di depannya memegang belati yang berdarah. Lokasi pemotretan untuk wilayah gambarannya adalah daerah yang gersang dan berlokasi wilayah tambak.

Pertarungan ini memiliki arti khusus dalam terminologi cerita rakyat Sarip Tambak Oso. Bahkan pada Ludrukan seringkali diangkat dalam pentas seni pertunjukan. Oleh karena itu, perlu direkam khusus dalam penelitian ini agar visualnya menjadi bahan refrensi berbagai pihak.
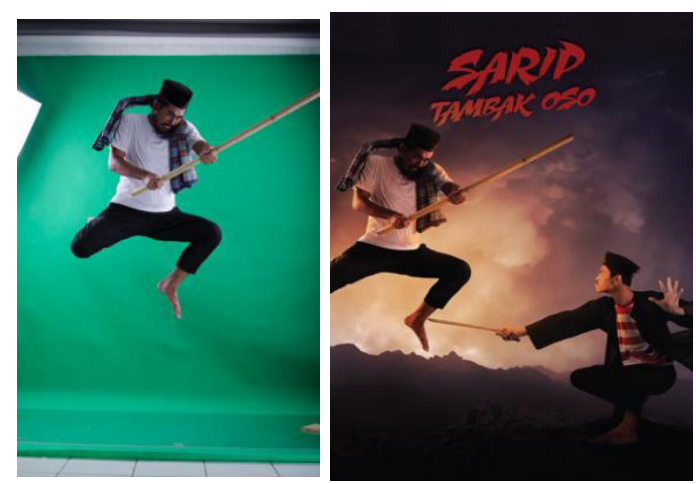

Gambar 15 Green Screen Visual Epic Pertarungan Paidi vs Sarip Tambak Oso (Perekaman gambar dilakukan di studio

Lab Fotografi Prodi DKV UPN 21 September 2020).

Visual pertarungan antara Sarip dan Paidi ini ditunjukkan dengan pose Paidi lebih menonjolkan diri dengan posisi di atas, sedangkan Sarip mengayunkan senjata. Representasi dalam gambar tersebut adalah sosok Sarip sebenarnya lebih dominan dalam riwayat ceritanya karena ada dukungan dari Belanda dibandingkan Sarip sebagai pejuang militan pada eranya. Agar visual ini terlihat dramatis dilakukan olah digital imaging dengan pengambilan gambar melalui studio fotografi dengan teknik green screen dan perekaman wilayah Tambak Oso kemudian digabungkan.

\section{Perekaman Kematian Sarip}

Kematian Sarip Tambak Oso ini hampir sama dengan tokoh-tokoh yang melawan Belanda pada daerah lain, yakni melalui skema pengkhianatan. Pelaku pengkhianatan ini adalah paman Sarip sendiri, yang menginformasikan 
kekuatan Sarip terletak pada ibunya. Dengan ibunya tidak mati, Sarip juga tidak bisa meninggal. Sekuel fotografi dalam visual ini ditunjukkan dengan visual Ibu Sarip tertembak karena menolak berkompromi dengan Belanda untuk menangkap Sarip.

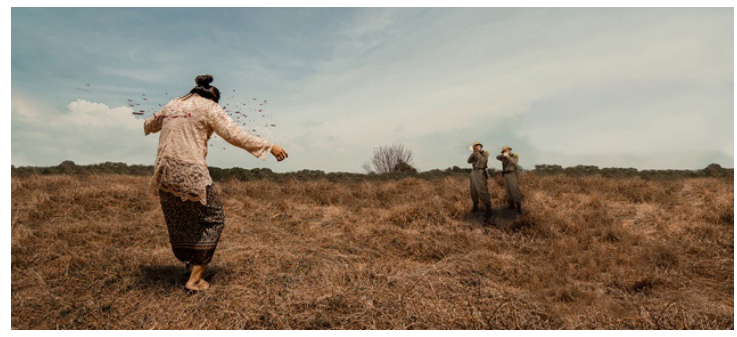

Gambar 16 Visual Ibu Sarip ditembak Belanda

(Perekaman gambar dilakukan 24 September 2020).

Setelah peristiwa terbunuhnya Ibu Sarip, Belanda otomatis dapat dengan mudah membunuh Sarip, setelah beberapa kali sebelumnya berusaha membunuhnya tetapi tidak berhasil. Penggambaran visual di akhir cerita sosok Sarip ini ditunjukkan dengan kematian Sarip yang tidak lagi kebal dengan senjata. Visual yang muncul adalah sosok Sarip yang tertembak dengan gestur tubuh yang jatuh ke belakang akibat terjangan peluru Belanda. Dalam kedua visual akhir cerita ini, pemilihan tone gambar ditunjukkan melalui warna sephia yang lebih dominan. Tujuannya agar membuat visual dramatis terkait akhir cerita sosok Sarip Tambak Oso.

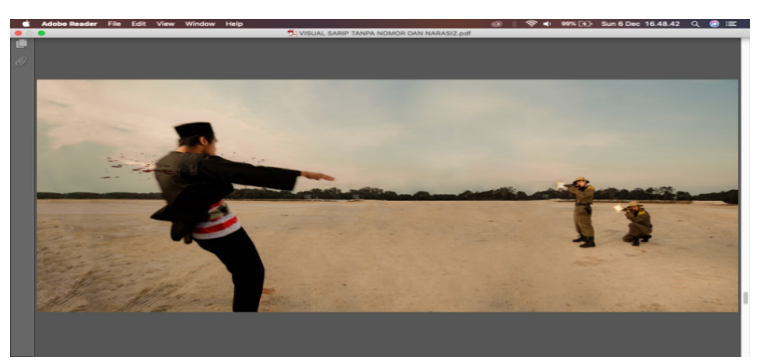

Gambar 17 Visual Sarip ditembak Belanda (Perekaman gambar dilakukan 1 Oktober 2020).

\section{SIMPULAN}

Rekonstruksi fotografi untuk visual cerita rakyat perlu perencanaan yang berjenjang dan mendalam. Tahapan awal dari penelitian ini yang paling penting adalah membuat pola perencanaan yang mendasari pembentukan visual cerita rakyat ke tahapan berikutnya. Perencanaan tersebut meliputi tiga tahapan penting dalam pengembangan cerita rakyat dalam Sarip Tambak Oso. Pertama, uraian cerita dari setiap literatur dan observasi oleh narasumber penelitian. Kedua, pemilihan lokasi yang merepresentasikan definisi cerita rakyat Sarip Tambak Oso. Ketiga, uraian teknis visual, apakah visual fotografi ini akan diambil melalui perekaman outdoor atau indoor. Dari tiga tahapan tersebut, cerita rakyat ini akan menjadi fondasi rekonstruksi visual cerita rakyat lainnya, untuk dikembangkan dan mendukung kebudayaan lokal yang tidak populer lagi.

\section{UCAPAN TERIMA KASIH}

Ucapan terima kasih kepada mahasiswa DKV, UPN sebagai tim survei dan tim teknis penelitian: Kernedy Saputro, Arvinsyah Ibrahim, Adrian Ferdi, dan Danar Rizky. Terima kasih untuk Program Studi DKV, UPN Veteran Jatim dan LPPM UPN Veteran Jatim yang telah mendukung dan membiayai penelitian cerita rakyat ini dari awal hingga selesai.

\section{KEPUSTAKAAN}

Afrianto, D. T. (2014). Selendang Lurik: Lambang Keperkasaan PerempuanPerempuan Dusun Niten, Kelurahan Pogung, Kecamatan Cawas, Klaten (Sebuah Kajian Estetika). Jurnal Ornament Kriya ISI Surakarta, 11(02).

Ajidarma, S. G. (2016). Kisah Mata; Fotografi di Antara Dua Subjek: Perbincangan Tentang Ada. Yogyakarta: Galang Press.

Arsita, A., \& Aji, D. T. (2020). Eksplorasi Jukstaposisi Visual dalam Novel Grafis The Photographer. Jurnal Rekam, 
16(01), 37-44. https://doi.org/10.24821/ rekam.v16i1.3853

Galloway, J. (1992). Seeing the Invisible: Photography in Science (Photography: At The Frontier Between Art And Science). Taylor and Francais.

Gibbs, L. S. (2018). Faces of Tradition in Chinese Performing Arts. Journal of Folklore Research, 55(01), 1-19. https:// doi.org/10.2979/jfolkrese.55.1.01

Gusal, L. O. (2015). Nilai-Nilai Pendidikan dalam Cerita Rakyat Sulawesi Tenggara Karya La Ode Sidu. Jurnal Humanika, 03(15).

Herlina, N. A. (2005). Nilai Edukatif Cerita Rakyat Tolaki. Pusat Kantor Bahasa Sulawesi Tenggara Depdiknas.

Janottama, I. P. A., \& Putraka, A. N. A. (2017). Gaya dan Teknik Perancangan Ilustrasi Tokoh pada Cerita Rakyat Bali. Segara Widya: Jurnal Hasil Penelitian dan Pengabdian Masyarakat Institut Seni Indonesia Denpasar, 05(1), 25-41. https://doi.org/10.31091/sw.v5i0.189

Kartika, E. D. (2018). Perlindungan Hukum Atas Cerita Rakyat yang Ditulis oleh Pencipta dalam Rangka Benefit Sharing. Jurnal Hukum \& Pembangunan, 48(02), 379-392. http://dx.doi.org/10.21143/ jhp.vol48.no2.1669

Koentjaraningrat. (2009). Pengantar Ilmu Antropologi. Bandung: Rineka Cipta.

Malinda, L. (2018). Sarep Tambak Oso. https://www.youtube.com/ watch? $=$ dmlLqMEyv9A

Mashuri, \& Nilofar, N. (2008). Peran Ibu Dalam Cerita Sarip Tambak Oso. Surabaya: Balai Bahasa Surabaya.

Mullen, L. (1998). Truth In Photography: Perception, Myth And Reality In The Postmodern World. Florida: University of Florida.

Purwaningsih, I. (2019). Kecamatan Waru dalam Angka. BPS Kabupaten Sidoarjo.

Sholihatin, E. (2013). Apakah Pisuhan Selalu Bermakna Negatif ?: Fungsi Pisuhan dalam Masyarakat Arek dan Masyarakat Mataraman. Jurnal Mozaik, 13(02), 158-167. http://dx.doi.org/10.20473/ mozaik.v13i2.3843

Sopudin. (2019). Kajian Struktur dan Nilai Budaya Cerita Rakyat Palabuhanratu.
Jurnal Lokabasa, 10(01), 100$107 . \quad$ https://doi.org/10.17509/jlb. v10i1.16948

Surahman, S. (2016). Determinisme Teknologi Komunikasi dan Globalisasi Media Terhadap Seni Budaya Indonesia. Jurnal Rekam, 12(01), 31-42. https:// doi.org/10.24821/rekam.v12i1.1385

Wardhani, J. K. (2019). Dramaturgi Ludruk Karya Budaya Mojokerto Jawa Timur Lakon Sarip Tambak Oso. SATWIKA: Jurnal Kajian Budaya dan Perubahan Sosial, 03(01).

Widodo, D. (2013). Sidoarjo Tempo Doeloe. Surabaya: Dukut Publishing.

Wulandari, A., \& Maryani, Z. (2017). Fotografi Potret Wanita Penambang Pasir di Lereng Selatan Gunung Merapi, Daerah Istimewa Yogyakarta. REKAM: Jurnal Fotografi, Televisi, Animasi, 13(01), 53-66. https://doi.org/10.24821/rekam. v13i1.1578

Yuwono, U. (2007). Gerbang Sastra Indonesia Klasik. Jakarta: Wedatama Widya Sastra. 